\title{
Evaluating the environmental effects of transportation modes using an integrated methodology and an application
}

\author{
*U. R. Tuzkaya \\ Department of Industrial Engineering, Mechanical Faculty, Yildiz Technical University, \\ 34349 Istanbul, Turkey \\ Received 10 August 2008; revised 17 November 2008; accepted 13 January 2009; available online 1 March 2009
}

\begin{abstract}
The increasing needs for transportation of freight and passengers causes environmental impacts. Preventing studies for these impacts should be considered by logistics firms and encouraged by the regulations of authorities. An important contribution can be provided by determining the environmental effects of the transportation modes in specific regions and using the most convenient ones. In this study, multiple criteria decision-making techniques, including human judgments, tangible and intangible criteria and priorities are used. Fuzzy analytic hierarchy process and preference ranking organization method for enrichment evaluation, as two of the multi criteria decision-making methodologies, are integrated for ranking the transportation modes in terms of the environmental effects of them. The proposed decision-making process is applied to chose the environmentally convenient transportation mode with respect to the determined evaluation criteria in Marmara Region of Turkey. The results indicate that, the main problem for the Marmara Region about transportation aspects is to pass from the intensive utilization of the road transportation mode to another one. In this study it is seen that the most convenient transformation mode in Marmara Region is the sea transportation mode.
\end{abstract}

Keywords: Decision-making techniques, transportation modes, multi criteria decision-making, fuzzy approach

\section{INTRODUCTION}

Transportation systems can increase the productivity and quality of life at the same time if they are planned and managed properly. Although the needs of people stimulate the demand for transportation, environmental pollution and health care which are also very important for the people. The transportation systems should ensure efficient movements of passengers and freights but, such a system should not deplete the natural resources and badly affects the environment. Although the cost of transportation is mostly chosen as the main evaluation criterion for transportation mode selection, many criteria should be considered to prefer a transportation mode to another. Today, the transportation systems are getting more complex structures in all around the world. Therefore, as the decision makers transfer big investment budgets to shape the future of transportation systems, they should analyze many criteria beside the creterion of cost.

Roles of transportation modes in transportation system decisions are very important. There are some

\section{ब*Corresponding Author Email: tuzkaya@yildiz.edu.tr}

Tel.: +902123832873 countries in Europe that restrict the usage of specific transportation modes considering their environmental effects. For example, in some countries, transit passes of the trucks are permitted only on a rail flat car or some transportation projects which use multimodal systems encouraged by the governments or unions. One of the main reasons of imposing people to use or to integrate specific transportation modes is to decrease the various environmental effects. While transportation systems expand and become more integrated, their impacts on the physical environment (air, water and land resources) will become more complex (Rondinelli and Berry, 2000).

Measuring the environmental effects of transportation modes may be a complex process because of the different criteria which approach to the subject from different aspects. Under certain conditions, determining the effects of transportation modes on environment may seem more explicit. However, the criteria that contain uncertainties or cannot be given precisely are usually expressed in linguistic terms by decision makers. This makes fuzzy logic a more natural approach to these kinds of 
problems. Because of the difficulty of obtaining certain data, such as non-normalized fuzzy ratings and fuzzy weights, fuzzy-logic based multi criteria decisionmaking (MCDM) methods may be efficiently applied to the problem of determining the effects of transportation modes on environment. Moreover, the fuzzy analytic hierarchy process (Fuzzy-AHP) methodology can be used to cope with uncertain human judgments. When the environmental criteria are considered, most of them contain linguistic terms and imprecise judgments. Therefore, the fuzzy-AHP methodology is used to determine the environmental criteria weights. There is not a similar study in literature that applies fuzzy-AHP methodology on transportation projects considering with environmental effects. Following the fuzzy-AHP step, another MCDM technique preference ranking organization method for enrichment evaluation (PROMETHEE) is chosen to rank the alternative transportation modes because of its easiness comparing with the other MCDM techniques. Integration of these two methodologies for decision-making in environmental issues makes this study unique. This integration completes each technique by overcoming the obstacles of separately using of them.

The characteristics of the transportation modes and the environmentally evaluation criteria are discussed detailed in section 2. Literature reviews and the explanations of the materials and methods are given in section 3 . In section 4 , the application of the integrated methodology is presented and the results and some scenarios analyses are discussed. This research has been done in Yildiz Technical University, in Istanbul, Turkey, during the period of January-July 2008.

\section{Transportation modes and environmental impacts}

Sometimes, it may not be possible to use one transportation mode instead of the other because of the geographical, infrastructural, freight type, etc. reasons. However, the advantages and disadvantages of transportation modes should be considered for transportation projects. The characteristics of the transportation modes are summarized below (Rondinelli and Berry, 2000; Tuzkaya and Önüt, 2008).

Rail transport is the most commonly used mode for heavy and bulky loads over long land hauls (in general, greater than or equal to $200 \mathrm{~km}$ ) without paying enormous charges. Trains can provide reasonably high speed and they are conveniently linked with other modes of transportation. Some of the advantages are constancy, low-cost guarantee, greater reliability and they are not affected by the weather and traffic conditions. The main disadvantages are inflexibility and specified routes between fixed terminals; moreover, they do not stop at intermediate points. From the environmental aspect on railway, there are some damages caused from improper fueling; maintenance and cleaning rail car, locomotives and parts; oil and coolant releases. However, using electricity power in railway instead of the fuel or oil derivatives decreases these undesirable environmental effects.

For door-to-door transportation, the most widely used mode is road transportation. Its main benefits are the flexibility and the ability to reach rugged terrains. The ease of freight loading/unloading, lack of necessity for rigid timetables and the existence of widespread transit roads are advantageous. The disadvantages are high maintenance and fuel expenses, weight limitations and duties in transit countries. Also, fuel combustion, motor oil, brake and transmission fluids, coolants, solvents, etc. pollute the air, soil and water.

Rail and road modes are limited to land use; however, an important part of international trade is carried out by sea transport. Sea transportation can be classified into three basic types: river and canals, coastal shipping and ocean transport. The main advantage of sea transportation is the ability to transport large amounts of bulk freights, liquids and containerized freights by ships and vessels. In addition, it is the cheapest transportation mode and there are no duty or transit-passing transactions between the starting and arrival points; however, the damage risk is high, transit times are long and there is a limitation and inflexibility with regard to finding appropriate ports. Bilge pumping waste disposal, tank cleaning, fueling are also harmful for water.

Air transportation is the most convenient mode when slow speed is unacceptable. Loading and unloading operations can be carried out frequently and the flexibility level can be increased. However, aircraft operations create noise, engine emissions and waste disposal problems.

In addition this study focuses on the environmental effects. According to the conditions, the importance of the environmental effects shows differences. Because of this situation, specific criteria are chosen by considering related literature (Goldman and Gorham, 
2006; Qureshi and Huapu, 2007; Shiftan et al., 2003) and the necessities of the application region. The explanations of the nine evaluation criteria used in this study are given below.

\section{Noise}

Noise is one of the most obvious and oftenmentioned negative impact of transportation traffic. Obviously, noise impacts vary by vehicle type, condition, location and time. For example, in road mode, tire-road noise is an important part of the vehicle noise. Different road surfaces may also give a large variation in noise levels. In addition, the engine of vehicle or the wrongly loaded freight can cause undesirable noises. As a result, comparing the noise impact of the transportation mode, the number of the people affected by noise is important. A comparison can be realized among the transportation modes since the noise costs are higher in urban areas and there are more human ears.

\section{Emission reduction potential}

Emissions of greenhouse gases are related with the risk of generating environmentally undesirable gases during the transportations. Main effects of the emissions are shown on human health, climate change, and ozone damage. Social cost of a transportation mode consists of two major components. First one is capital and operating costs paid by users and all other costs that result from the use of the transportation mode, but, which are not paid for directly by users (Delucchi et al., 1996). Emission values are considered in second one and combustion of the each energy resource type has different carbon, sulfur and nitrogen emissions. Aiming the reduction of emission values in transportation enforces to utilize specific transportation modes.

\section{Effects on open land and wild life}

Transportation modes cause different effects on open land and wild life. For example, created noise, produced emissions, risks of accidents pollute the open lands and wildlife areas. Moreover, the greenhouse effect from the combustion of the fuel in transportation vehicle causes global warming which is destructive for open land and wildlife.

\section{Undesirable view}

In general, transportation vehicles do not have good views. There is a risk of bad looking that can be constituted according to the freight or the container. The transportation modes and their networks which pass through the urban sites increase undesirable view risks.

\section{Safety}

This criterion may be explained as the ratio of transportations concluding in an accident to all transportations in a determined time period. The possibility of the accidents and the related environmental effects shows differences according to the transportation modes.

\section{Energy resource utilization}

This criterion is related with the amount of energy resource consumption per unit freight. The fuel consumption of a motor vehicle is a function of a number of characteristics of the vehicle and the trip: the size of the engine, the weight of the vehicle, the aerodynamic drag of the vehicle, the average speed of the trip, the number of stops and starts, the amount of time spent idling, etc. (Delucchi et al., 1996). The consumed energy type is also important since the specific modes are dependent on specific energy resources. Especially, the fossil oil and its derivatives are the limited resources. But at the same time, they are the mostly used ones. Considering with these characteristic, tending to transportation modes which can use the alternative and environmental friendly energy resources are preferable.

\section{Transportation capacity of the vehicle}

As explained in the previous sections, different vehicles are used in each transportation mode and their unit capacities are not the same. Transportation of a specific freight can required only one ship instead of hundreds of trucks. Therefore, the capacity of the vehicle can change the environmental effects comprehensively.

\section{Infrastructure of the transportation network}

This criterion represents the infrastructure quality of the routes between the points of departure and the destinations. Asphalt quality and the lane numbers of roads; signalization and rail quality of railways; port conditions and connection possibilities of sea and air ports may be listed as the infrastructure quality of the transportation network. 


\section{Seasonal affects}

Transportation modes are sensitive to seasonal affects. For example, the maritime transportation is dependent on rigors of weather and its tardiness possibility is greater than the railway transportation. In this instance, the criterion measures the responses rate of transportation between demand and supply points in terms of the seasonal effects.

Literature review of the used MCDM, different application areas and the studies integrating them are detailed in this section. Then, the mathematical explanations of the methods are given.

\section{Literature review of the used methods}

MCDM is an important branch of decision-making approaches. It deals with the decision problems under the presence of a number of decision criteria. MCDM is divided into multi objective decision-making (MODM) and multi attribute decision-making (MADM) (Climaco, 1997). In MODM, there are not predetermined alternatives for choosing one or ranking them. Instead of including alternatives, MODM tries to optimize more than one objective function subject to a set of constraints. At least, the obtained solution is the most efficient one and it is not possible to improve the performance of an objective function without decreasing the performance of one other objective function. However, in MADM, there is a set of alternative solutions to be evaluated against a set of attributes which are difficult to quantify (Pohekar and Ramachandran, 2004).

Analytic hierarchy process (AHP) is one of the most frequently applied MADM methods for various problem types. The AHP provides an easy to use framework for the decision makers by giving the opportunity of assessing the weights of each criterion with a nominal nine-point (1-9) scale. It is also available for fuzzy weights (Zimmermann, 1987). The AHP uses hierarchic or network structures to represent a decision problem and then develops priorities for the alternatives based on the judgments of decision-maker throughout the system (Saaty, 1980). The reason of adopting AHP especially for the qualitative performance data is the fact that qualitative factors are often complicated and conflict. In addition, the user acceptability and confidence in the analysis provided by the AHP methodology is high when it is compared with other MADM methods (Zakarian and Kusiak, 1999). Although the AHP has various benefits and usefulness, several shortcomings have been reported in the literature and some modifications are suggested to deal with these shortcomings. The AHP tries to capture a decision maker's knowledge but, it has not the ability of fully reflecting the human thinking style. In other words, the AHP approach is incapable of handling the inherent subjectivity and ambiguity associated with the mapping of one's perception to an exact number (Pan, 2008). Linguistic and vague descriptions could not be solved easily by the AHP unless by the development of fuzzy decision-making. Comparison of decision maker's uncertain judgments with fuzzy logic can constitute more rational and accurate results. Considering with this problems, Buckley (1985) developed a fuzzy-AHP model and after this study various developments of fuzzy-AHP methods and applications have been carried out (Chang, 1996; Wang et al., 2007). Fuzzy version of the AHP was applied to various areas in the literature. Some of the recently published studies are given as follows. Huang et al. (2008) used fuzzy-AHP for selection of government sponsored research and development project in Taiwan. Wang and Chin (2008) proposed a method for fuzzy-AHP which utilizes a linear goal programming model to derive normalized fuzzy weights for fuzzy pairwise comparison matrices. A hybrid model that uses concepts from fuzzy logic and the AHP was proposed for transportation route choice by Arslan and Khisty (2005). Also, a more general version of fuzzyAHP, fuzzy analytic network process, was applied for transportation mode selection considering eight main and thirty two sub-criteria by Tuzkaya and Onut (2008). They applied the proposed approach for a logistic service provider's transportation project between Turkey and Germany. However, application of the fuzzyAHP methodology on transportation projects considering with the environmental effects cannot be seen in literature.

Weak preferences or incomparability are usually observed in environmental decisions. Therefore, the usage of other MCDM methods can be required sometimes. For example, ELECTRE (the elimination and choice translating reality) method has the capability of handling discrete quantitative and qualitative criteria in nature and provides complete ordering of the alternatives. Besides, this approach has shortcomings through its complexity and nuances in the comparisons. To overcome ELECTRE's obstacles, ranking method PROMETHEE (preference ranking organization 
method for enrichment evaluation) has been developed в у в r a в s et al., 1986 and the flexibility and simplicity has been brought together for the users. It can be adapted to problems where finite number alternatives are ranked considering weighted and sometimes conflicting specific criteria. Implementation of this method is constituted from seven steps which details will be given in the next section. First six steps of the calculations give the partial precedence and named as PROHETHEE I. In the seventh step, the net precedence of the alternatives is obtained for a complete ranking of all alternatives and named as PROMETHEE II.

This ranking method has been widely used for various application areas in the literature. Meanwhile, some of the recent studies include fuzzy numbers because of the difficulty of defining the data within a reasonable degree of accuracy. In one of the recent study, PROHETHEE was used in the first step of the decision-making process related to evaluating the outsourcers (Araz et al., 2007). Pohekar and Ramachandran (2004) prepared a review study related to the application of PROMETHEE and other MCDM methods on sustainable energy planning. Another application was in iron and steel making industry for outranking the environmental assessment (Geldermann et al., 2000). Again an extended version of PROMETHEE was used in this study to handle the fuzzy data on preferences, scores and weights. Using PROMETHEE, suitable ecotechnology method for evaluating was realized in Taiwan by Chou et al. (2007). Indices of ecotechnology methods were linked with construction sites and a practical construction case located in Shihmen reservoir watershed was chosen for evaluation and verification.

There are some studies such as Macharis et al. (2004) in determining operational synergies in multi criteria analysis, De Brucker et al. (2004) in evaluation of intelligent transportation systems, Wang and Yang (2007) in information systems outsourcing, etc. that handle these two MCDM methods together in different areas. However, this study is unique for using integration of fuzzy-AHP and PROMETHEE on an environmental issue.

\section{MATERIALS AND METHODS}

Two step methodology: Fuzzy-AHP and PROMETHEE

The proposed methodology is developed with the AHP and PROMETHEE frameworks. The first step of the methodology is using the AHP technique with fuzzy logic. The weights of the criteria, which are used in PROMETHEE for ranking the transportation modes, are gained by fuzzy-AHP calculations. In the second step, another multi criteria method, PROMETHEE, is applied for the evaluation and ranking the alternative transportation modes.

\section{Fuzzy-AHP methodology}

Fuzzy set theory was introduced by Zadeh (1965) to deal with vague, imprecise and uncertain problems. This theory has been used as a modeling tool for complex systems that are hard to define precisely, but can be controlled and operated by humans (Dweiri, 1999). More detailed discussions related to fuzzy sets, fuzzy relations and fuzzy operations can be found in Ross (2004).

Embedding the AHP method into fuzzy sets, another application area of fuzzy logic is revealed. Decision makers usually find that it is more confident to give interval judgments than fixed value judgment. This is because usually it is unable to explicit about the preferences due to the fuzzy nature of the comparison process (Kahraman et al., 2004).

In this study, Chang (1996) extent analysis method is preferred, since the steps of this approach are relatively easier than the other fuzzy-AHP approaches and similar to the crisp AHP. The steps of Chang's extent analysis approach, by integrating the improvements of Zhu et al. (1999), are as follows. Let $X=\left\{x_{1}, X_{2}, \ldots, x_{n}\right\}$ be an object set and $U=\left\{u_{1}, u_{2}, \ldots, u_{m}\right\}$ be a goal set. Each object is taken and extent analysis for each goal, $g_{i}$, is performed, respectively. Therefore, $m$ extent analysis values for each object can be obtained, with the following signs:

$M_{g_{i}}^{1}, M_{g_{i}}^{2}, \ldots, M_{g_{i}}^{m} i=1,2, \ldots, \mathrm{n}$

Where, all the $M_{g_{i}}^{j}(j=1,2, \ldots, m)$ are triangular fuzzy numbers (TFNs).

The steps of Chang extent analysis can be given as follows:

Step 1: The value of fuzzy synthetic extent with respect to the ith object is defined as:

$$
S_{i}=\sum_{j=1}^{m}{\stackrel{j}{g_{i}}}_{j} \otimes\left[\sum_{i=1}^{n} \sum_{j=1}^{m} M{ }_{g_{i}}^{j}\right]^{-1}
$$


To obtain $\sum_{j=1}^{m} M_{g_{i}}^{j}$, the fuzzy addition operation of $m$ extent analysis value for a particular matrix should be performed as:

$$
\sum_{j=1}^{m} M_{g_{i}}^{j}=\left(\sum_{j=1}^{m} l_{j}, \sum_{j=1}^{m} m_{j}, \sum_{j=1}^{m} u_{j}\right)
$$

and to obtain $\left[\sum_{i=1}^{n} \sum_{j=1}^{m} M_{g_{i}}^{j}\right]^{-1}$, the fuzzy adition operation of $M_{g_{i}}^{j}(j=1,2, \ldots, m)$ values can be performed as follows:

$$
\sum_{i=1}^{n} \sum_{j=1}^{m} M_{g_{i}}^{j}=\left(\sum_{i=1}^{n} l_{i}, \sum_{i=1}^{n} m_{i}, \sum_{i=1}^{n} u_{i}\right)
$$

and then, the inverse of the vector in Eq 4 is computed in the following order:

$$
\left[\sum_{i=1}^{n} \sum_{j=1}^{m} M_{g_{i}}^{j}\right]^{-1}=\left(\frac{1}{\sum_{i=1}^{n} u_{i}}, \frac{1}{\sum_{i=1}^{n} m_{i}}, \frac{1}{\sum_{i=1}^{n} l_{i}}\right)^{(5)}
$$

Step 2: The degree of possibility of

$M_{2}=\left(l_{2}, m_{2}, u_{2}\right) \geq M_{1}=\left(l_{1}, m_{1}, u_{1}\right)$ is defined as

$V\left(M_{2} \geq M_{1}\right)=\sup _{y \geq x}\left[\min \left(\mu_{M_{1}}(x), \mu_{M_{2}}(y)\right)\right]$

and can be equivalently expressed as follows:

$V\left(M_{2} \geq M_{1}\right)=h g t\left(M_{1} \cap M_{2}\right)=\mu_{M_{2}}(d)=$

$$
\left\{\begin{array}{cl}
1, & \text { if } m_{2} \geq m_{1} \\
0, & \text { if } l_{1} \geq u_{2} \\
\frac{l_{1}-u_{2}}{\left(m_{2}-u_{2}\right)-\left(m_{1}-l_{1}\right)} & \text { otherwise }
\end{array}\right.
$$

Where, $d$ is the ordinate of the highest intersection point between $\mu_{M_{1}}$ and $\mu_{M_{2}}$ to compare $M_{1}$ and $M_{2}$ and both the values of $V\left(M_{1} \geq M_{2}\right)$ and $V\left(M_{2} \geq M_{1}\right)$ are needed.

Step 3: The possibile degree for a convex fuzzy number to be greater than $k$ convex fuzzy numbers

$$
\begin{aligned}
& V\left(M \geq M_{1}, M_{2} \ldots, M_{k}\right)= \\
& V\left[\left(M \geq M_{1}\right) \text { and }\left(M \geq M_{2}\right) \text { and } \ldots \text { and }\left(M \geq M_{k}\right)\right](8) \\
& =\min V\left(M \geq M_{i}\right), \quad i=1,2,3, \ldots, k .
\end{aligned}
$$

Assume that

$d^{\prime}\left(A_{i}\right)=\min V\left(S_{i} \geq S_{k}\right)$

For; $k=1,2, \ldots, n$ and $k \neq i$ then, the weight vector is given by

$W^{\prime}=\left(d^{\prime}\left(A_{1}\right), d^{\prime}\left(A_{2}\right), \ldots, d^{\prime}\left(A_{n}\right)\right)^{\mathrm{T}}$,

Where, $A_{i}(i=1,2, \ldots, n)$ are $n$ elements.

Step 4: The normalized weight vectors via normalization are:

$W=\left(d\left(A_{1}\right), d\left(A_{2}\right), \ldots, d\left(A_{n}\right)\right)^{\mathrm{T}}$,

Where, $W$ is a nonfuzzy number.

PROMETHEE methodology

The explanation and mathematically calculation steps of the PROMETHEE are summarized below and more information can be found in Araz et al. (2007) and Geldermann et al. (2000).

Let $i$ represents the alternatives $(i=1,2, \ldots, m$ and $i \in A), j$ represents the set of criteria $(j=1,2, \ldots, n$ and $j \in C)$ and $g_{j}(i)$ is the value of criterion $j$ of alternative $i$. After the $g_{j}(i)$ values are determined in the first step, preference function $F_{j}\left(i, i^{\prime}\right)=g_{j}(i)-g_{j}\left(i^{\prime}\right)=x_{j}$, which is the preference degree of alternative $i$ in comparison to $i^{\prime}$ in terms of criterion $j$, is defined with one of the six different generalized shapes given in Fig. 1 with Eq. 12-17 (Brans et al., 1986). The names of generalized criteria functions are usual criterion, quasi criterion, criterion with linear preference, level criterion, criterion with linear preference and indifference area and Gaussian criterion. $q$ and $p$ are the indifference and strict preference thresholds of a specific criterion, respectively.

$$
\begin{aligned}
& p(x)= \begin{cases}0, & x \leq 0 \\
1, & x>0\end{cases} \\
& p(x)= \begin{cases}0, & x \leq q \\
1, & x>q\end{cases} \\
& p(x)=\left\{\begin{array}{cc}
0, & x \leq q \\
x / p, & q<x<p \\
1, & x \geq p
\end{array}\right.
\end{aligned}
$$



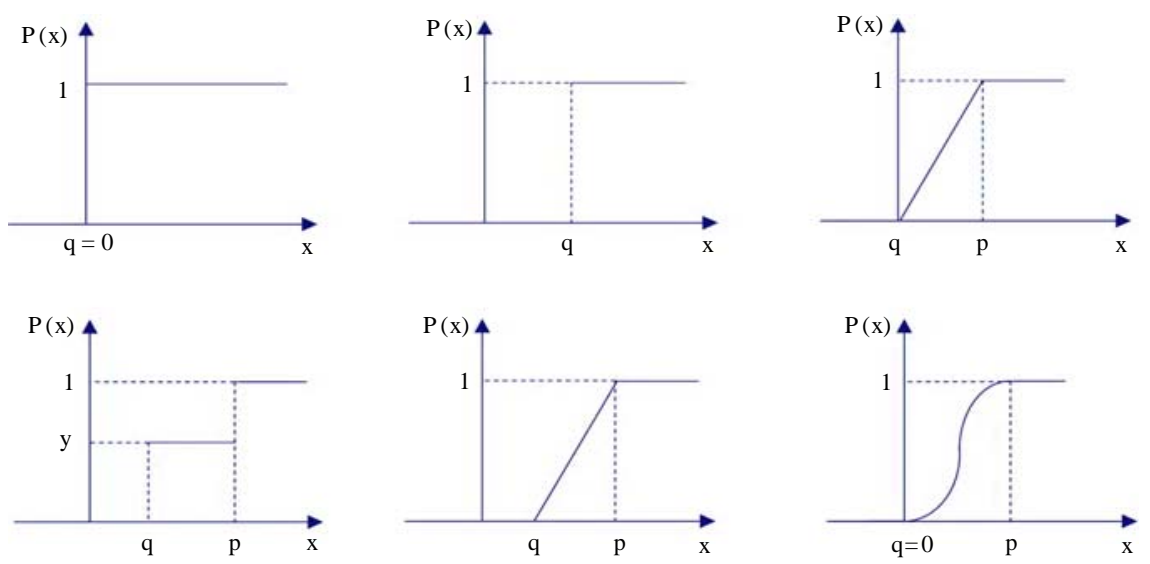

Fig. 1: Generalized preference functions

$$
\begin{aligned}
& p(x)=\left\{\begin{array}{rr}
0, & x \leq q \\
y, & q<x<p \\
1, & x \geq p
\end{array}\right. \\
& p(x)=\left\{\begin{aligned}
0, & x \leq q \\
(x-q) /(p-q), & q<x<p \\
1, & x \geq p
\end{aligned}\right. \\
& p(x)=\left\{\begin{aligned}
0, & x \leq q \\
1-e^{-x^{2} / 2 z^{2},} & q<x<p \\
1, & x \geq p
\end{aligned}\right.
\end{aligned}
$$

Then, the aggregated preference functions are calculated for each alternative pair using the preference functions obtained in the previous step. The next step is calculating the preference index $\pi\left(i, i^{\prime}\right)$ with Eq 18 which is a weighted average of preference functions $P\left(x_{j}\right)$ for all the criteria. Here, $w_{j}$ is the weight assigned to criterion $j$ and it is obtained from the fuzzy-AHP evaluations.

$$
\pi\left(i, i^{\prime}\right)=\frac{\sum_{j=1}^{n} w_{j} P\left(x_{j}\right)}{\sum_{j=1}^{n} w_{j}}
$$

Sum of the $\pi\left(i, i^{\prime}\right)$ is used as a measure of the strength of the alternative $i \in A$ and is named as leaving flow. Thus, leaving flow yields a measure of the outranking character of $i$ as given in Eq. (19).

$$
\begin{gathered}
\phi^{+}(i)=\frac{1}{m-1} \sum_{i^{\prime}=1}^{m} \pi\left(i, i^{\prime}\right) \quad \forall i \in A \\
i^{\prime} \neq i
\end{gathered}
$$

Another measure for the weakness of the alternative $i \in A$ is entering flow. This is the outranking character of alternative $i$ as given in Eq. (20).

$$
\begin{gathered}
\phi^{-}(i)=\frac{1}{m-1} \sum_{\substack{i^{\prime}=1 \\
i^{\prime} \neq i}}^{m} \pi\left(i^{\prime}, i\right) \\
\end{gathered}
$$

By the above calculations, required results are obtained for PROMETHEE-I and PROMETHEE-II. The PROMETHEE-I partially preorders the alternatives by comparing the leaving and entering flows and determines the weak preferences and incomparability of alternatives. When one of the Eqs. 21-23 are provided, alternative $i$ is superior to $i^{\prime}$.

$$
\begin{aligned}
& \phi^{+}(i)>\phi^{+}\left(i^{\prime}\right) \text { and } \phi^{-}(i)<\phi^{-}\left(i^{\prime}\right) \\
& \phi^{+}(i)>\phi^{+}\left(i^{\prime}\right) \text { and } \phi^{-}(i)=\phi^{-}\left(i^{\prime}\right) \\
& \phi^{+}(i)=\phi^{+}\left(i^{\prime}\right) \text { and } \phi^{-}(i)<\phi^{-}\left(i^{\prime}\right)
\end{aligned}
$$

If the Eq. 24 is realized, alternative $i$ and $i^{\prime}$ have the same preferences.

$\phi^{+}(i)=\phi^{+}\left(i^{\prime}\right)$ and $\phi^{-}(i)=\phi^{-}\left(i^{\prime}\right)$ 
At least, alternative $i$ and $i^{\prime}$ are incomparable, when one of the Eqs 25-26 is provided.

$$
\begin{aligned}
& \phi^{+}(i)>\phi^{+}\left(i^{\prime}\right) \text { and } \phi^{-}(i)>\phi^{-}\left(i^{\prime}\right) \\
& \phi^{+}(i)<\phi^{+}\left(i^{\prime}\right) \text { and } \phi^{-}(i)<\phi^{-}\left(i^{\prime}\right)
\end{aligned}
$$

Even the partial preorders derived by PROMETHEEI contain realistic information, complete preorders are requested generally. This is yielded by calculating the net flows as the difference of leaving and entering flows which is called as PROMETHEE-II given in Eq. 27:

$$
\phi^{\text {net }}(i)=\phi^{+}(i)-\phi^{-}(i) \text {. }
$$

\section{RESULTS AND DISCUSSION}

\section{The application}

The proposed methodology selects the most convenient transportation mode considering the effects of them on environmental issues. The study is focused on Marmara Region in Turkey. Geographical position of Marmara Region allows to use all of the transportation modes for national, international and transit transportations. Furthermore, there are many transshipment points for transit passes of freights and passengers in Marmara Region. This situation also increases the importance of multimodal transportation which includes using at least two transportation modes in a journey. This is important because of reducing the bad affects of specific modes by decreasing the rate of using them in transportation.

There are eleven cities in Marmara Region. Istanbul is the most crowded city in Turkey and it is also the center of many industries, trades and cultures. Many of the remaining cities in Marmara Region such as Kocaeli, Bursa, Yalova, Adapazari and Tekirdag are more important cities in terms of the per capita income (Fig. 2). As a result, the traffic levels of the transportation modes are very high in this region. TransEuropean Motorway, which is the motorway network constituted by the participation of many European countries, passes from the Marmara Region. Being a member of this network increases the road transportation intensity very much. Besides, TransEuropean Railway which passes from Marmara Region is the same formation in railway network and increases the railway traffic. In addition, there are many large and small size sea ports in the region which of them are mostly placed in Istanbul and then in Kocaeli, Balikesir and Tekirdag. The container, dry-bulk and liquid freight capacities of the ports in the region increase consistently. There are also 7 main airports generally in the centers of these cities. When the intensities are compared in terms of the constituted traffic of the transportation modes, it is seen that the road transportation is the first one. However, many transshipment points can be used to transfer the freight from road to sea or railway transportation modes. Therefore, multimodal transportation alternative is added considering the effects of it to the environment. In Fig. 2, the railways are denoted with blue lines sea routes are denoted with red lines and the main airports are specified with red circles. In the first step of the study, the criteria explained previously are selected by a decision-making group. This group is constituted from different areas, i. e. academicians, government, municipality, environmental associations and logistics firms. Then, the group decides on the convenient transportation modes to evaluation process. Road, railway, sea, air and multimodal transportation modes are chosen because of the possibility of using them in Marmara Region of Turkey for national and international transportation and transit passes. Fig. 3 shows the structure of the evaluation criteria and alternatives. Firstly, the precedence of the criteria in terms of the goal of determining the most environmentalist transportation mode is calculated by fuzzy-AHP.

\section{First step calculations: Fuzzy-AHP}

As mentioned in the previous sections, fuzzy-AHP is used for determining the weights of the criteria to be used in PROMETHEE calculation steps. Before starting the pair-wise comparisons of the criteria, six linguistic terms and their corresponding triangular fuzzy numbers are decided with the decision makers. Correspondence of the linguistic terms "absolute, very strong, fairly strong, strong, weak, and equal" can be given as $(5,6,7)$, $(4,5,6),(3,4,5),(2,3,4),(1,2,3),(1,1,1)$, respectively. The first step is the preparing the comparison matrix of used criteria by decision-making group. As shown in Table 1 , the comparisons of the criteria according to the main goal are realized by fuzzy triangular numbers. Then, using the Eq. 2, the values of fuzzy synthetic extent with respect to the each criterion are calculated as given below:

$S_{C 1}=(5.75,8.53,12.75) \ddot{A}(1 / 91.57,1 / 131.40,1 / 176.40)$ $=(0.033,0.065,0.139)$ 
Int. J. Environ. Sci. Tech., 6 (2), 277-290, Spring 2009

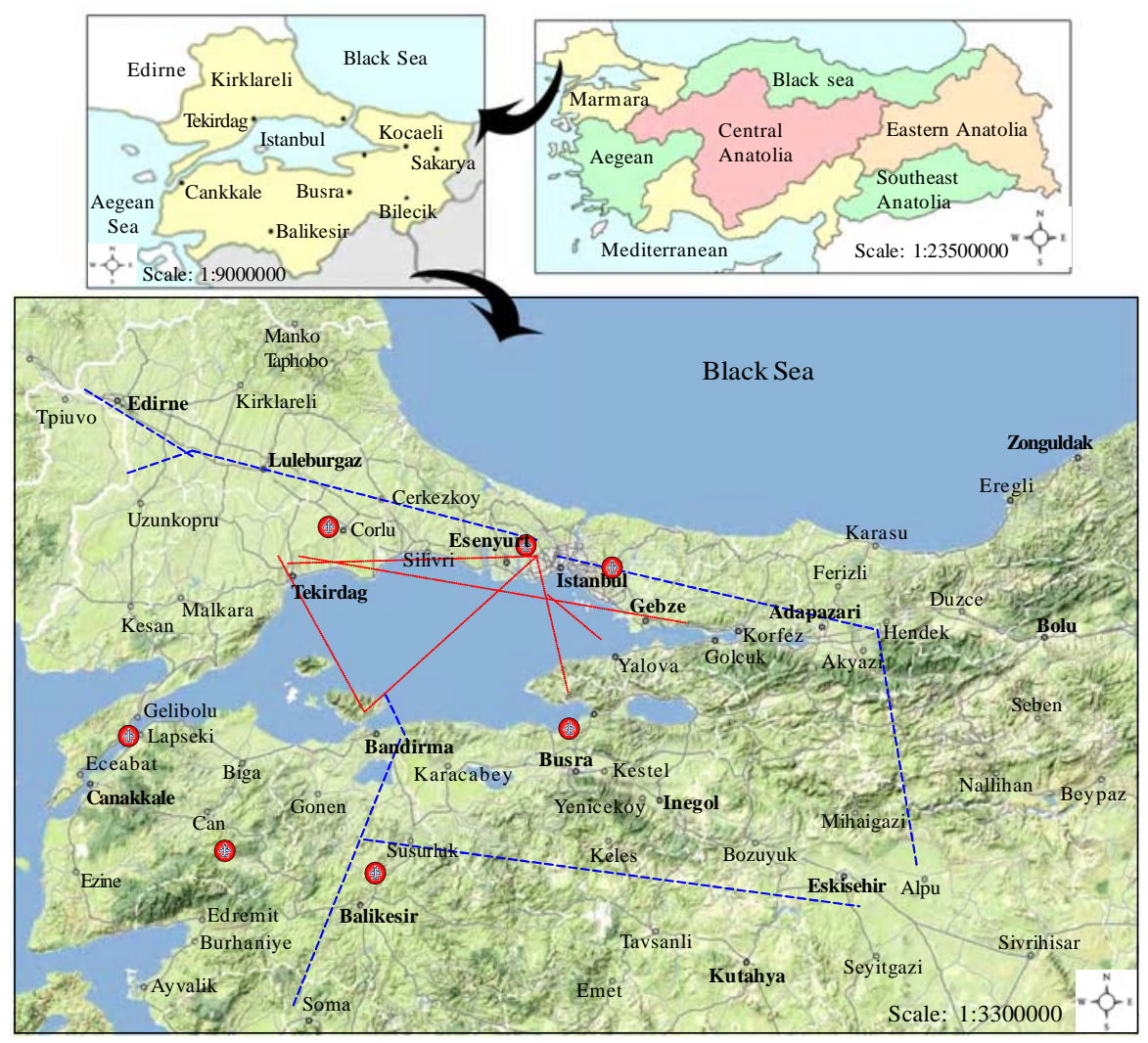

Fig. 2: Map of the Marmara Region

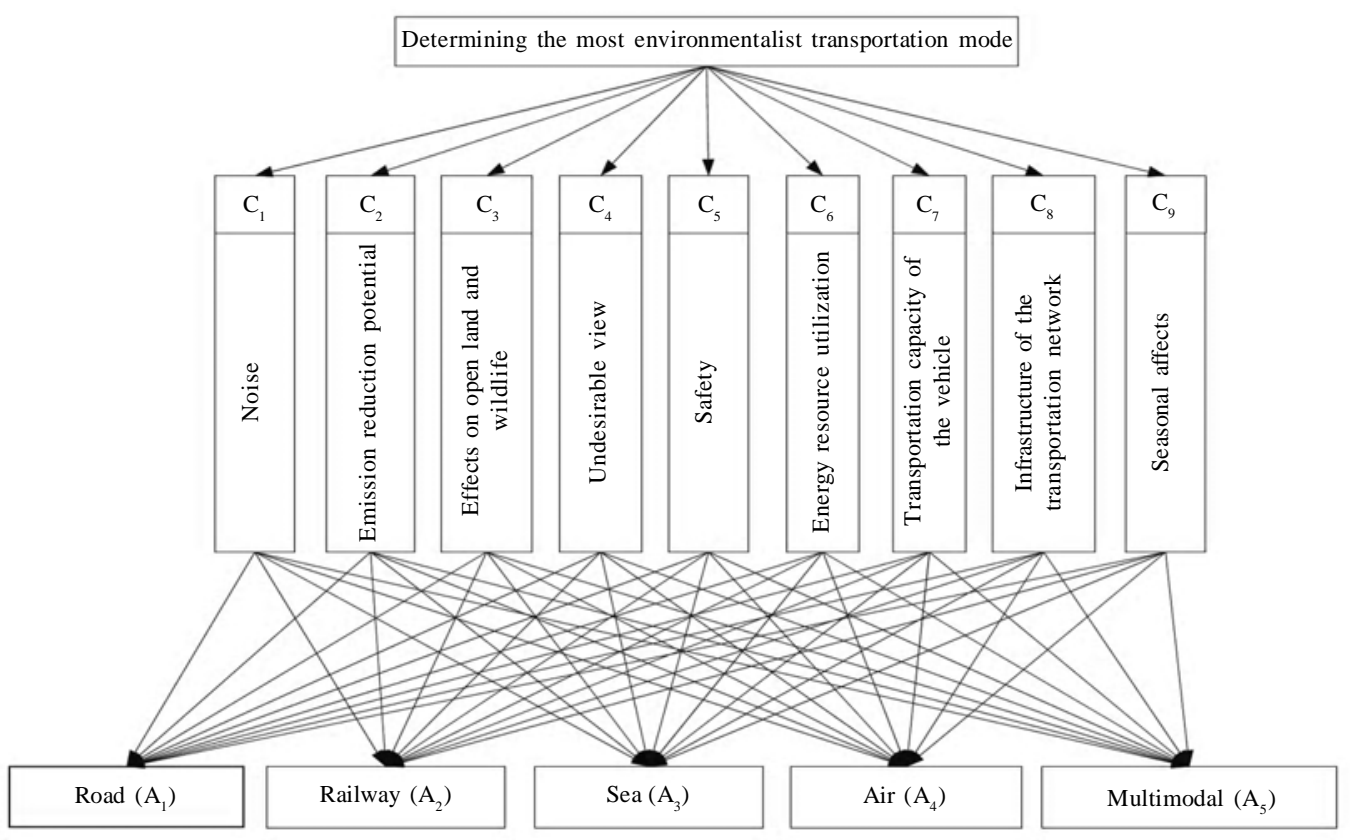

Fig. 3: Hierarchical structure of the criteria and alternatives 
U. R. Tuzkaya

Table 1: Matrix of criteria comparisons

\begin{tabular}{|c|c|c|c|c|c|c|c|c|}
\hline $\mathrm{C}_{1}$ & $\mathrm{C}_{2}$ & $\mathrm{C}_{3}$ & $\mathrm{C}_{4}$ & $\mathrm{C}_{5}$ & $\mathrm{C}_{6}$ & $\mathrm{C}_{7}$ & $\mathrm{C}_{8}$ & $\mathrm{C}_{9}$ \\
\hline$(1,1,1)$ & $(0.33,0.5,1)$ & $(0.33,0.5,1)$ & $(2,3,4)$ & $(0.25,0.33,0.5)$ & $(0.17,0.2,0.25)$ & $(1,2,3)$ & $(0.33,0.5,1)$ & $\begin{array}{l}(0.33,0.5,1) \\
\end{array}$ \\
\hline$(1,2,3)$ & $(1,1,1)$ & $(1,2,3)$ & $(4,5,6)$ & $(1,2,3)$ & $(2,3,4)$ & $(5,6,7)$ & $(2,3,4)$ & $(3,4,5)$ \\
\hline$(1,2,3)$ & $(0.33,0.5,1)$ & $(1,1,1)$ & $(3,4,5)$ & $(1,2,3)$ & $(0.33,0.5,1)$ & $(1,2,3)$ & $(0.25,0.33,0.5)$ & $(1,2,3)$ \\
\hline $.5,0.33,0.5)$ & $(0.17,0.2,0.25)$ & $(0.2,0.25,0.33)$ & $(1,1,1)$ & $(0.33,0.5,1)$ & $(0.14,0.17,0.2)$ & $(0.2,0.25,0.33)$ & $(0.2,0.25,0.33)$ & $(0.33,0.5,1)$ \\
\hline$(2,3,3)$ & $(0.33,0.5,1)$ & $(0.33,0.5,1)$ & $(1,2,3)$ & $(1,1,1)$ & $(0.25,0.33,0.5)$ & $(2,3,4)$ & $(0.25,0.33,0.5)$ & $(0.33,0.5,1)$ \\
\hline$(4,5,6)$ & $(0.25,0.33,0.5)$ & $(1,2,3)$ & $(5,6,7)$ & $(2,3,4)$ & $(1,1,1)$ & $(3,4,5)$ & $(2,3,4)$ & $(3,4,5)$ \\
\hline $0.33,0.5,1)$ & $(0.14,0.17,0.2)$ & $(0.33,0.5,1)$ & $(3,4,5)$ & $(0.25,0.33,0.5)$ & $(0.2,0.25,0.33)$ & $(1,1,1)$ & $(0.25,0.33,0.5)$ & $(0.33,0.5,1)$ \\
\hline$(1,2,3)$ & $(0.25,0.33,0.5)$ & $(2,3,4)$ & $(3,4,5)$ & $(2,3,4)$ & $(0.25,0.33,0.5)$ & $(2,3,4)$ & $(1,1,1)$ & $(2,3,4)$ \\
\hline$(1,2,3)$ & $(0.20,0.25,0.3)$ & $(0.33,0.5,1)$ & $(1,2,3)$ & $(1,2,3)$ & $(0.2,0.25,0.33)$ & $(1,2,3)$ & $(0.25,0.33,0.5)$ & $(1,1,1)$ \\
\hline
\end{tabular}

$S_{C 2}=(20.00,28.00,36.00) \ddot{\mathrm{A}}(1 / 91.57,1 / 131.40,1 /$

$176.40)=(0.113,0.213,0.393)$

$S_{C 3}=(8.92,14.33,20.50) \mathrm{Ä}(1 / 91.57,1 / 131.40,1 /$

$176.40)=(0.051,0.109,0.224)$

$S_{C 4}=(2.83,3.45,4.95) \mathrm{A}(1 / 91.57,1 / 131.40,1 / 176.40)$

$=(0.016,0.026,0.054)$

$S_{C 5}=(7.50,11.17,15.00) \ddot{\mathrm{A}}(1 / 91.57,1 / 131.40,1 /$

$176.40)=(0.043,0.085,0.164)$

$S_{C 6}=(21.25,28.33,35.50) \ddot{\mathrm{A}}(1 / 91.57,1 / 131.40,1 /$

$176.40)=(0.120,0.216,0.388)$

$S_{C 7}=(5.84,7.58,10.53) \ddot{A}(1 / 91.57,1 / 131.40,1 / 176.40)$

$=(0.033,0.058,0.115)$

$S_{C 8}=(13.50,19.67,26.00) \ddot{\mathrm{A}}(1 / 91.57,1 / 131.40,1 /$

$176.40)=(0.077,0.150,0.284)$

$S_{C 9}=(5.98,10.33,15.17) \mathrm{Ä}(1 / 91.57,1 / 131.40,1 /$

$176.40)=(0.034,0.079,0.166)$

At the last step, the $V$ values are calculated using the Eq. 7. Thus, the weight vector of the criteria are obtained from Eq.10 as $W_{c}=(0.029,0.260,0.130,0$, $0.066,0.263,0,0.187,0.065)^{\mathrm{T}}$.

The weight vector of the criteria, $W_{c}$, shows that the weights of the forth and the seventh criteria are zero and do not have any effect on the alternative transportation mode selection. Moreover, the second and sixth criteria have bigger effects on the selection process.

\section{Second step calculations: PROMETHEE}

The PROMETHEE method is applied for evaluating the transportation modes in terms of environmental effects of them. The weights of criteria, preference function types of them and related parameter values which are determined by the decision group is given in Table 2.

Some of the values of alternative transportation modes are easy to obtain quantitatively such as Noisy in $\mathrm{dB}$ (VTPI, 2006) and and emission values in $\mathrm{CO}_{2}$ g/ton.km (Den Boer et al., 2008). However, determining the values of alternatives in terms of the remaining criteria quantitatively is more difficult. Therefore, their values are determined in a brainstorming decision-making process by the decision-making group. The compromised qualitative values of the alternatives according to the criteria are given in Table 3 .

After choosing the evaluation criteria and the alternatives and determining the convenient preference function types and related parameter values for each criterion, preference function values can be calculated. As an example, $A_{1}$ (road) and $A_{2}$ (railway) alternative pair is considered. For the noise criterion $\left(\mathrm{C}_{1}\right), A_{1}$ is better than $A_{2}$. Because of the lower value is better, the absolute value of the difference is considered. Thus, the calculations are realized as follows:

$\mathrm{f}\left(A_{1}\right)-\mathrm{f}\left(A_{2}\right)=|80-100|=20$ and $P_{1}\left(A_{1}, A_{2}\right)=20 /(30-$ $0)=0.667$.

The similar calculations are realized for the undesirable view criterion $\left(\mathrm{C}_{4}\right)$ as shown below:

$\mathrm{f}\left(A_{1}\right)-\mathrm{f}\left(A_{2}\right)=|2-4|=2$ and $P_{4}\left(A_{1}, A_{2}\right)=2 /(4-0)=0.5$.

For the remaining criteria, alternative $A_{1}$ has worse values than the $A_{2}$. Therefore, the preference function values of $P_{2}\left(A_{1}, A_{2}\right), P_{3}\left(A_{1}, A_{2}\right), P_{5}\left(A_{1}, A_{2}\right), P_{6}\left(A_{1}, A_{2}\right)$, $P_{7}\left(A_{1}, A_{2}\right), P_{8}\left(A_{1}, A_{2}\right), P_{9}\left(A_{1}, A_{2}\right)$ are equal to 0 .

Then, the preference index can be constituted for $A_{1}$ and $A_{2}$ alternative pair as given in Eq. 28:

$\pi\left(A_{1}, A_{2}\right)=$

$\frac{0.029 * 0.667+0+0+0 * 0.5+0+0+0+0+0}{1}$

$=0.0194$

Same calculations are realized to obtain the preference indexes of each alternative pair as given in Table 4. 
Int. J. Environ. Sci. Tech., 6 (2), 277-290, Spring 2009

Table 2: Summary of the used data in PROMETHEE

\begin{tabular}{lrrrrrrrrr}
\hline & C1 & C2 & C3 & C4 & C5 & C6 & C7 & C8 & C9 \\
\hline Weights & 0.029 & 0.260 & 0.130 & 0 & 0.066 & 0.263 & 0 & 0.187 & 0.065 \\
Preference & V Shape & V Shape & V Shape & V Shape & V Shape & V Shape & V Shape & V Shape & V Shape \\
Function Type & Min & min & min & min & max & min & max & min & max \\
Max/Min & 0 & 0 & 0 & 0 & 0 & 0 & 0 & 0 \\
Indifference (Q) & -30 & -100 & -8 & -4 & 7 & -20 & 8 & -15 & 10 \\
Preference (P) & & & & & & & &
\end{tabular}

Table 3: The obtained values of the alternative transportation modes for each criterion

\begin{tabular}{|c|c|c|c|c|c|}
\hline & Road & Railway & Sea & Air & Multimodal \\
\hline Noise (dB) & 80 & 100 & 70 & 110 & 0 \\
\hline $\begin{array}{l}\text { Emission reduction } \\
\text { potential }\left(\mathrm{CO}_{2} \mathrm{~g} / \text { ton } \mathrm{km}\right)\end{array}$ & 114 & 42 & 31 & 2 & 57 \\
\hline $\begin{array}{l}\text { Effects on open } \\
\text { land and wildlife }\end{array}$ & 10 & 8 & 6 & 2 & 4 \\
\hline Undesirable view & 2 & 4 & 5 & 1 & 3.5 \\
\hline Safety & 5 & 8 & 6 & 12 & 7 \\
\hline $\begin{array}{l}\text { Energy resource } \\
\text { utilization }\end{array}$ & 7 & 4.5 & 1 & 22 & 5.95 \\
\hline $\begin{array}{l}\text { Transportation capacity } \\
\text { of the vehicle }\end{array}$ & 1 & 8 & 10 & 6 & 6.3 \\
\hline $\begin{array}{l}\text { Infrastructure of the } \\
\text { transportation network }\end{array}$ & 20 & 10 & 8 & 5 & 12 \\
\hline Seasonal affects & 15 & 20 & 10 & 12 & 18 \\
\hline
\end{tabular}

Using the obtained preference indices in Table 4, leaving and entering flows can be calculated. An example of leaving and entering flows calculation is given for $A_{1}$ in Eq. 29.

$$
\begin{aligned}
\phi^{+}\left(A_{1}\right) & =\frac{\pi\left(A_{1}, A_{2}\right)+\pi\left(A_{1}, A_{3}\right)+\pi\left(A_{1}, A_{4}\right)+\pi\left(A_{1}, A_{5}\right)}{5-1} \\
& =\frac{0.0194+0.0326+0.2459+0.0058}{5-1}=0.0759 \\
\phi^{-}\left(A_{1}\right) & =\frac{\pi\left(A_{2}, A_{1}\right)+\pi\left(A_{3}, A_{1}\right)+\pi\left(A_{4}, A_{1}\right)+\pi\left(A_{5}, A_{1}\right)}{5-1} \\
& =\frac{0.4383+0.5287+0.6428+0.3976}{5-1}=0.5019
\end{aligned}
$$

These calculations are repeated for the other alternatives and results of them are summarized in Table 5.

PROMETHEE I determines the partial precedence using $\phi^{+}(i)$ and $\phi^{-}(i)$ values in Eqs (21-26). As shown in Fig. 4, $A_{3}$ outranks $A_{2}$ and $A_{2}$ outranks $A_{5}$. $A_{1}$ is outranked by all other alternatives. However, it is not possible to compare $A_{3}, A_{2}$ and $A_{5}$ with $A_{4}$. Partial precedence of the alternatives is not sufficient to determine the best alternative.
Table 4: Calculated preference indexes for alternative transportation modes

\begin{tabular}{cccccc}
\hline & $A_{1}$ & $A_{2}$ & $A_{3}$ & $A_{4}$ & $A_{5}$ \\
\hline$A_{1}$ & & 0.0194 & 0.0326 & 0.2459 & 0.0058 \\
$A_{2}$ & 0.4383 & & 0.0839 & 0.2919 & 0.1055 \\
$A_{3}$ & 0.5287 & 0.1611 & & 0.2920 & 0.1983 \\
$A_{4}$ & 0.6428 & 0.3012 & 0.2469 & & 0.3098 \\
$A_{5}$ & 0.3976 & 0.0783 & 0.0939 & 0.2734 & \\
\hline
\end{tabular}

Table 5: Leaving and entering flows for alternative transportation modes

\begin{tabular}{cccccc}
\hline & $A_{1}$ & $A_{2}$ & $A_{3}$ & $A_{4}$ & $A_{5}$ \\
\hline$\phi^{+}(i)$ & 0.0759 & 0.2299 & 0.2950 & 0.3752 & 0.2108 \\
$\phi^{-}(i)$ & 0.5019 & 0.1400 & 0.1143 & 0.2758 & 0.1549 \\
\hline
\end{tabular}

When the complete precedence is obtained by PROMETHEE II, it is seen that the $A_{3}$ is the best one and $A_{4}$ is placed between the $A_{3}$ and $A_{2}$. The complete ranks of the alternative $A_{3}, A_{4}, A_{2}, A_{5}$ and $A_{1}$ are 0.181, 0.099, $0.090,0.056,-0.426$, respectively.

\section{RESULTS AND DISCUSSION}

The complete the ranking with PROMETHEE II shows that sea transportation mode is the best alternative, when the entire criteria are considered. The precedence values 


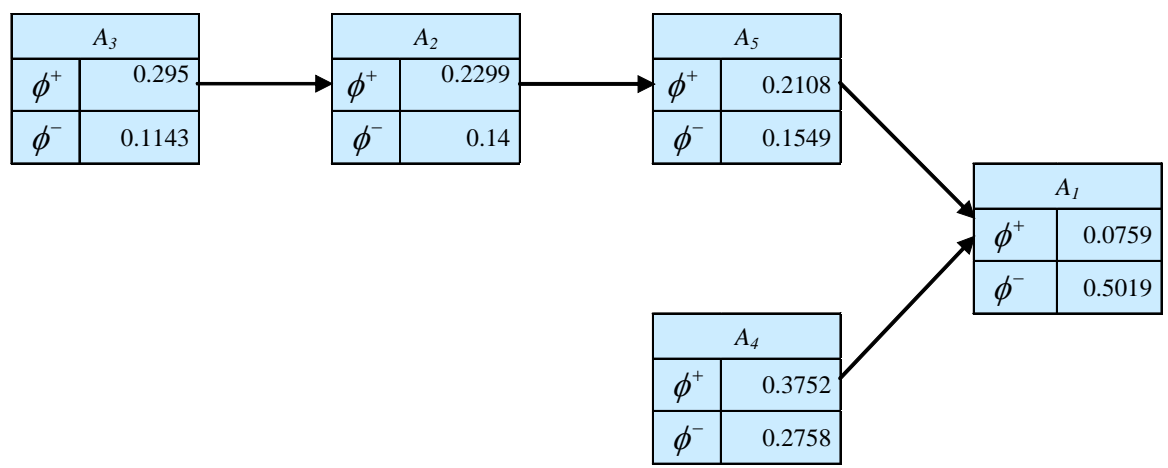

Fig. 4: Partial ranking with PROMETHEE I

of air and railway transportation modes are close to each other. Multimodal transportation alternative takes all the advantages and disadvantages at the same time. Therefore, it is better than the road alternative, but takes only the fourth place in the ranking. The road transportation is the worst environmental affecting alternative. The numerical values of net flows also show that the gap between road transportation mode and the others are very high. This is a critical result because the worst chosen alternative is the mostly used one in Marmara Region. However, to realize a deeper analysis and to validate the obtained results, some scenarios were considered. The results were reached according to the obtained criteria weights with fuzzy-AHP. Even the fuzzyAHP methodology was used and the uncertainties were taken into account for determining the criteria weights, evaluating the rank of alternatives in terms of the changes in criteria weights is important. This is also required for justifying the model. The obtained results of the different scenarios are proved that there is not an inconsistency in the model and it is working as expected. The weights of the criteria were changed in four different scenarios. The first scenario neglects the criteria weights. In other words, the equal weights were assumed for PROMETHEE calculations. This scenario showed that the net flow values of alternatives were changed, but only the ranks of first alternative (sea) and the second alternative (air) were affected Fig. 5. Besides, it can be mentioned that the normal results showed the preferences more explicitly, but the equal weights brought the net flow values closer.

Second scenario changes the weights of the criteria which are ranked in first two $\left(\mathrm{C}_{2}\right.$ and $\left.\mathrm{C}_{6}\right)$ and last two $\left(\mathrm{C}_{4}\right.$ and $\mathrm{C}_{7}$ ) places. This scenario is also important for validating the model to show that changing the weights oppositely changes the preferences oppositely too. The results were obtained in the expected manner and larger decreases in sea and railway alternatives and increases in air alternative were observed. This means that decreasing in "the emission reduction potential" and "energy resource utilization" criteria removes the attractiveness of the sea and railway alternatives. Besides, air transportation is better in undesirable view and transportation capacity of the vehicle.

The third scenario increases the intensities of first two placed criteria, $\mathrm{C}_{2}$ and $\mathrm{C}_{6}$. The aim of this scenario is to reach the marginal points towards the inclination of the decision-making group. $50 \%$ precedence was given to each two $\mathrm{C}_{2}$ and $\mathrm{C}_{6}$ and the remaining criteria were neglected by giving $0 \%$ weights. This situation supported the original results by increasing the magnitudes of the precedence of the alternatives. Thus, precedence of the rail and sea alternatives were reached to top points and precedence of the air alternative was failed to the forth places with a very low net flow value.

The last scenario is the reverse of the third scenario and $50 \%$ precedence was given to each two $\mathrm{C}_{4}$ and $\mathrm{C}_{7}$, which have zero weight in the original solution and the remaining criteria were neglected by giving $0 \%$ weights. This scenario was also realized to validate the proposed methodology from the opposite side. The results were very similar to the second scenario results, but they were more striking because of sharing out the total weight to only $\mathrm{C}_{4}$ and $\mathrm{C}_{7}$. The road transportation mode alternative was ranked as the last alternative for the original solution and for each scenario. Since this alternative took the worst values for most of the criteria, changing the criteria weights did not affect deeply the net flow value of the road transportation alternative. The preference of the multimodal transportation did not change deeply in any scenario. Since the multimodal transportation includes all transportation modes, it is generally balanced in criteria weight changes. Its place 
was changed between second and forth places. After the overall analysis, it is seen that even though the road alternative is preferred intensively in Marmara Region in real life; sea, air and railway transportation alternatives should be taken into account in terms of the environmental effects. Air transportation is ranked as the second alternative in original solution, but its rank decreases when the weights of the higher value taken criteria are increased. In addition, transporting many freight types is not possible by air transportation mode. All these indications focus on the usage of sea or railway transportation modes instead of road transportation mode. In the east-west line in Marmara, use of railway and sea modes are convenient. For example, the line run along from Tekirdag to Izmit provides to decrease road intensity in Bosphorus bridges in Istanbul and related environmental effects. Also, the railway alternative can be used in that line, but there is a disconnection again in Bosphorus and passing that point with ferryboat take over the multimodal transportation alternative. In the north-south line in Marmara again, the sea transportation is practicable instead of going around the Marmara Sea by road transportation mode. However, it is not very suitable to use railway in that line because of the lack of infrastructure investments.

As a result, the main problem is to pass from road to an alternative mode. As it is seen, the most convenient mode alternative in Marmara is the sea transportation mode. There are many crowded cities in Marmara and many other environmentally bad effecting points such as heavy industries, disposal collection points, wastes poured out to sea, etc. Minimizing the environmental effects caused by transportation such as, noisy, emissions, energy usage, etc. will provide a big benefits for people, sea, air and open lands of the region.

\section{CONCLUSION}

This study represents the environmental effects of alternative transportation modes and a decision-making process to rank them considering the environmental criteria. Nine criteria are determined by an environmentalist group to choose one among the five alternative transportation modes in Marmara Region of Turkey. Two MCDM method is integrated by a decision making group to obtain a realistic and usable result.

The main contribution of the study is to combine many environmental criteria and to synthesizing them in a two step integrated solution approach. Applying this approach in a specific region, considering dynamics and specifications of this region and obtaining valid and reasonable results are other important points. The evaluation of the decision-making group was also examined with different scenarios and the consistency of the obtained results was proved.

In future studies, different MCDM methods may be tried to combine for determining the similarities and differences between the obtained results and decision processes. As another direction, this study may be considered as a pilot application to extend this analysis to entire country with more criteria or sub-criteria for determining strategic transportation policies.

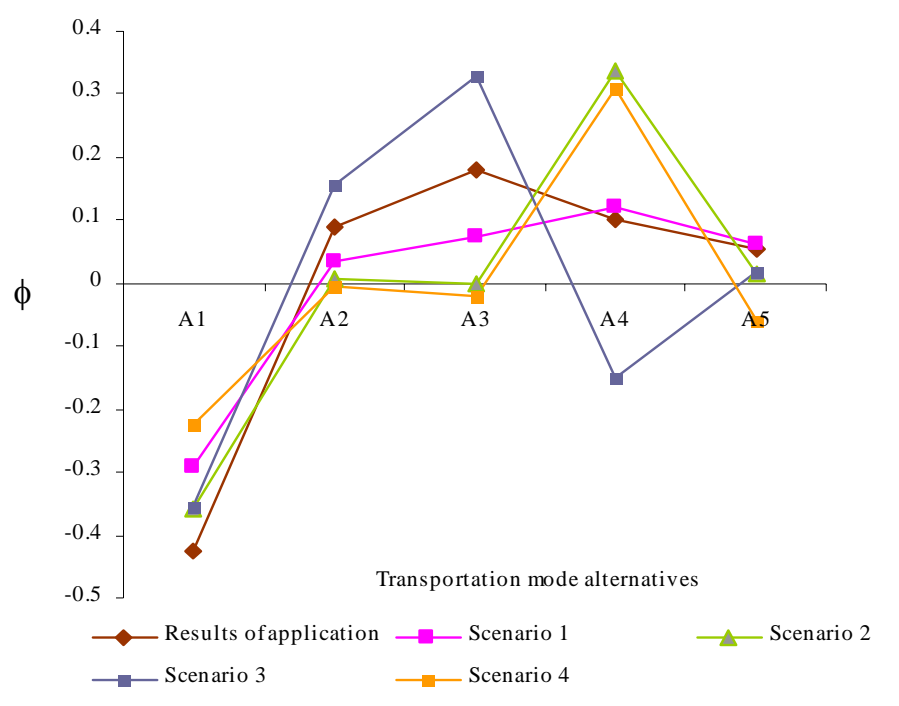

Fig. 5: Ranking of the alternatives according to the scenario analysis 


\section{REFERENCES}

Araz, C.; Ozfirat, P. M.; Ozkarahan, I., (2007). An integrated multicriteria decision-making methodology for outsourcing management. Compu. Oper. Res., 34 (12), 3738-3756 (19 pages).

Arslan, T.; Khisty, C. J., (2005). A rational reasoning method from fuzzy perceptions in route choice. Fuzzy Set. Syst., 150 (3), 419-435 (17 pages).

Brans, J. P.; Vincke, B. H.; Mareschal, B., (1986). How to select and how to rank projects: The PROMETHEE method. Eur. J. Oper. Res., 24 (2), 228-238 (11 pages).

Buckley, J. J., (1985). Fuzzy hierarchy analysis. Fuzzy Set. Syst., 17 (3), 233-247 (15 pages).

Chang, D. Y., (1996). Applications of the extent analysis method on fuzzy AHP. Eur. J. Oper. Res., 95 (3), 649-655 (7 pages).

Chou, W. C.; Lin, W. T.; Lin, C. Y., (2007). Application of fuzzy theory and PROMETHEE technique to evaluate suitable ecotechnology method: A case study in Shihmen Reservoir Watershed, Taiwan. Ecol. Eng., 31 (4), 269-280 (12 pages).

Climaco, J. (1997). Multicriteria analysis. New York: SpringerVerlag.

De Brucker, K.; Verbeke, A.; Macharis, C., (2004). The applicability of multicriteria-analysis to the evaluation of intelligent transport systems (ITS). Res. Transport. Econ., 8 (1), 151-179 (21 pages).

Delucchi, M. A.; Wang, M. Q.; Ceerla, R., (1996). Emissions of criteria pollutants, toxic air pollutants and Greenhouse gases, from the use of alternative transportation modes and fuels. Institute of Transportation Studies, University of California, Davis, Research Report UCD-ITS-RR-96-12.

den Boer, L. C.; Brouwer, F. P. E.; van Essen, H. P., (2008). STREAM, Studie naar transport emissions van alle modaliteiten. Rapport VERSIE 1.0, CE Delft, Oplossingen voor milieu, economie en technologie.

Dweiri, F., (1999). Fuzzy development of crisp activity relationship charts for facilities layout. Comput. Ind. Eng., 36 (1), 1-16 (16 pages).

Geldermann, J.; Spengler, T.; Rentz, O., (2000). Fuzzy outranking for environmental assessment, Case study: Iron and steel making industry. Fuzzy Set. Syst., 115 (1), 45-65 (21 pages).

Goldman, T.; Gorham, R., (2006). Sustainable urban transport: Four innovative directions. Tech. Soc., 28, 261-273 (13).

Huang, C. C.; Chu, P. Y; Chiang Y. H., (2008). A fuzzy AHP application in government-sponsored R\&D project selection. Omega, 36 (6), 1038-1052 (15 pages).

Kahraman, C.; Cebeci, U.; Ruan, D., (2004). Multi-attribute comparison of catering service companies using fuzzy AHP: The case of Turkey. Int. J. Prod. Econ., 87 (2), 171-184 (14 pages).
Macharis, C.; Springael, J.; De Bruckerc, K.; Verbeke, A., (2004). PROMETHEE and AHP: The design of operational synergies in multi criteria analysis. Strengthening PROMETHEE with ideas of AHP. Eur. J. Oper. Res., 153 (2), 307-317 (11 pages).

Pan, N. F., (2008). Fuzzy AHP approach for selecting the suitable bridge construction method, Automation in Construction. 17 (8), 958-965 (8 pages).

Pohekar, S. D.; Ramachandran, M., (2004). Application of multi-criteria decision making tosustainable energy planning - A review. Renew. Sust. Energ. Rev., 8, 365-381 (17 pages).

Qureshi, I. A.; Huapu, L., (2007). Urban transport and sustainable transport strategies: A case study of Karachi, Pakistan. Tsinghua Sci. Tech., 12 (3), 309-317 (9 pages).

Rondinelli, D.; Berry, M., (2000). Multimodal transportation, logistics and the environment: Managing interactions in a global economy. Eur. Manag. J., 18 (4), 398-410 (13 pages).

Ross, T. J., (2004). Fuzzy Logic with Engineering Applications, $2^{\text {nd. }}$ (Ed.), John Wiley and Sons Ltd.

Saaty, T. L., (1980). The analytic hierarchy process. RWS Publications, Pittsburgh, PA.

Shiftan, Y.; Kaplan, S.; Hakkert, S., (2003). Scenario building as a tool for planning a sustainable transportation system. Transport. Res. D-Tr. E., 8 (5), 323-342 (20 pages).

Tuzkaya, U. R.; Önüt, S., (2008). A fuzzy analytic network process based approach to transportation- mode selection between Turkey and Germany: A case study. Inform. Sci., 178 (15), 3132-3145 (14 pages).

VTPI, (2006). Transportation Cost and Benefit Analysis - Noise Cost, Victoria Transport Policy Institute, Guide Book, Canada.

Wang, J. J.; Yang, D. L., (2007). Using a hybrid multi-criteria decision aid method for information systems outsourcing. Comput. Oper. Res., 34 (12), 3691-3700 (10 pages).

Wang, L.; Chu, J.; Wu, J., (2007). Selection of optimum maintenance strategies based on a fuzzy analytic hierarchy process. Int. J. Prod. Econ., 107 (1), 151-163 (13 pages).

Wang, Y. M.; Chin, K. S., (2008). A linear goal programming priority method for fuzzy analytic hierarchy process and its applications in new product screening. Int. J. Approx. Reason. 49 (2), 451-465 (15 pages).

Zadeh, L. A., (1965). Fuzzy sets. Inform. Control, 8 (3), 338353 (18 pages).

Zakarian, A.; Kusiak, A., (1999). Forming teams: An analytical approach. IIE Trans., 31 (1), 85-97 (13 pages).

Zhu, K.; Jing, Y.; Chang, D., (1999). A discussion on Extent Analysis method and applications of fuzzy AHP. Eur. J. Oper. Res., 116 (2), 450-456 (6 pages).

Zimmermann, H. J., (1987). Fuzzy sets, Decision-making and expert systems, Kluwer, Boston. 